Article

\title{
Novel Cost Reduction Method for Wind Farms Associated with Energy Storage Systems by Optimal Kinetic Energy Control
}

\author{
Kenta Koiwa ${ }^{1, *(\mathbb{D})}$, Takuro Tawara ${ }^{1}$, Mizuki Watanabe ${ }^{1}$, Kang-Zhi Liu ${ }^{1}\left(\mathbb{D}\right.$, Tadanao Zanma ${ }^{1}(\mathbb{D}$ \\ and Junji Tamura ${ }^{2}$ (D) \\ 1 Department of Electrical and Electronic Engineering, Chiba University, Chiba 263-8522, Japan; \\ Takuro.Tawara@nttdata.com (T.T.); mimimizoooon@gmail.com (M.W.); kzliu@faculty.chiba-u.jp (K.-Z.L.); \\ zanma@chiba-u.jp (T.Z.) \\ 2 Department of Electrical and Electronic Engineering, Kitami Institute of Technology (KIT), \\ Hokkaido 090-8507, Japan; tamuraj@mail.kitami-it.ac.jp \\ * Correspondence: kenta.koiwa@chiba-u.jp; Tel.: +81-43-290-3345
}

Received: 29 September 2020; Accepted: 13 October 2020; Published: 16 October 2020

\begin{abstract}
Wind power generation provides an attractive method for tackling global environmental issues. However, the power grid cannot accommodate large amount of wind farms (WFs) because the fluctuation of WF output degrades the power quality (frequency and voltage) in the power grid. Technical requirements that are related to WF power fluctuation are issued in many countries in order to introduce the WF without degrading power quality. Therefore, it is essential to smooth the WF output in order to satisfy the technical requirements. This paper proposes an operation methodology for a system that is composed of energy storage systems (ESSs) and WF by kinetic energy (KE) control. Moreover, an optimal KE control is presented. The economical aspect and the advantage of the proposed system are verified through scenario simulations.
\end{abstract}

Keywords: wind power generation; output smoothing; kinetic energy; optimization; energy storage systems

\section{Introduction}

Wind power generation is spotlighted because of global warming and the depletion of fossil fuels, etc. [1]. If a large number of wind farms (WFs) are introduced to the power systems, it leads to a solution to the above issues, since thermal power generation in the power system is reduced. However, the power quality, such as frequency and voltage in the power system, is degraded because WF output constantly fluctuates with wind speed [2-4]. In the worst case, the power system may get unstable. Therefore, it is essential to smooth the WF output to maintain the power quality. In fact, technical requirements that are related to WF power fluctuation are issued in many countries [5-7].

To this end, three main approaches: energy storage system (ESS) (battery, superconducting magnetic energy storage system, or flywheel, etc.) [4,6-14], pitch angle control [15-17], and kinetic energy (KE) [18-21] control have been studied. The ESS is the most widely used in these approaches. However, its cost is very high. Some control schemes that reduce the rated power (the rated capacity) of the ESS have been proposed. A first-order low-pass filter (FLF) is usually used in ESS control systems [8-10]. Although the FLF is simple, a large rated ESS power is required. To improve the FLF, complex methods (optimal FLF [6,7], high-order filter [4], Kalman filter [13], fuzzy control [11], and machine learning method [12], etc.) have been proposed. Nevertheless, it is difficult to reduce the rated power (the rated capacity) of the ESS sufficiently. A simple controller composed of a gain and a second-order high-pass filter was proposed in [14]. This controller can reduce the rated power of the 
ESS more than the FLF. However, further cost reduction is desired in order to smooth the output of large-scale WFs.

The pitch angle control can smooth wind generator (WG) output without an ESS [15-17]. The implementation of the pitch angle control is easy and its installation cost is inexpensive. However, the WG output significantly decreases, since blades of the WG are operated in order to release the wind. It implies that the profit significantly decreases. In addition, the increase of mechanical stress and fatigue of the WG is inevitable. Therefore, it is impractical for the WG output to be smoothed by the pitch angle control.

The KE control has been proposed in order to smooth the WG output without releasing the wind [18-21]. The KE stored in the rotor of the WG can be used to smooth the WG output. When the smoothing command is received, the rotating mass releases or absorbs energy via rotor speed deceleration/ acceleration. The control system is simple and easy to implement, as is the case of pitch angle control. Nevertheless, the operating point of the WG is shifted from the maximum power point. It implies that there is a trade-off between the WG output smoothing and the generating efficiency. Therefore, the reduction of the generating efficiency is inevitable in the KE control, although the efficiency of WG with KE control is higher than that with pitch angle control [18-20]. In addition, the available KE of the WG is much less than the energy of ESS. As a result, it is hard to satisfy the technical requirement (see Section 2.4) with only the KE control.

Table 1 summarizes the characteristics of standard smoothing methods. Because these methods have both advantages and disadvantages, it is difficult to achieve both cost reduction and WF output smoothing by a single method. Methods that coordinate these systems may achieve a good trade-off between these two objection. Although the system without ESS is attractive, there is no better way to replace the ESS completely, as discussed above.

This paper proposes a system that is composed of ESS and WF operated by the KE control. In addition, we present a coordination method for the ESS and WF via the optimization of the KE control. The optimal KE control can consider the trade-off between smoothing the WG output and the generating efficiency. As a result, the efficiency of the WG can be increased with the KE controller. The KE control was developed in [18] for a single WG. We generalize it to fit for all WGs in the WF. Moreover, an economical aspect of the KE control is revealed through scenario simulations. The advantage of the proposed system is verified by a comparative analysis with the standard system that is composed of ESS and WF operated by maximum power point tracking (MPPT).

The rest of the paper is organized, as follows: Section 2 describes the overall system under consideration. Section 3 briefly reviews the standard MA KE control and presents the optimal KE control for the WF. The cost calculation method is investigated for the proposed system with the ESS and the WF operated by the KE control in Section 4. The effectiveness of the proposed system is verified based on the cost comparison and scenario simulations with real wind data in Section 5 . Section 6 concludes this paper.

Table 1. Comparison between different smoothing methods.

\begin{tabular}{lcccc}
\hline Method & Cost & Efficiency & Mechanical Stress & Smoothing Effect \\
\hline ESS & Expensive & Good & - & Excellent \\
Pitch angle control & Inexpensive & Poor & Poor & Good \\
Kinetic energy control & Inexpensive & Good & Excellent & Poor \\
\hline
\end{tabular}

\section{System Description}

\subsection{System Configuration}

Figure 1 shows the system configuration. In Figure $1, n$ is the number of WGs, $V_{i}(i=1,2, \cdots, n)$ is the wind speed, $\omega_{i}(i=1,2, \cdots, n)$ is the mechanical rotor angular frequency, $P_{i}(i=1,2, \ldots, n)$ 
is the WG output, $P_{\mathrm{WF}}\left(=\sum_{i=1}^{n} P_{i}\right)$ is the WF output, $P_{\mathrm{b}}$ is the ESS output, and $P_{\mathrm{g}}\left(=P_{\mathrm{WF}}-P_{\mathrm{b}}\right)$ is the power that is supplied to the power system called combined output power. Note that the positive sign of $P_{\mathrm{b}}$ implies power charge of the ESS. First, the WF output is smoothed by the KE control in the proposed system. Subsequently, the WF output is mitigated by the ESS in order to satisfy the technical requirement. The cost can be reduced, since the KE control can reduce the peak power of the WF output. Namely, the rated power of the ESS can be reduced.

When it is clear from the context, a continuous-time signal $x(t)$ or a discrete-time signal $x[k]$ is simply denoted by $x$ (For simplicity, $x[k]=x\left(k T_{\mathrm{s}}\right.$ ) is used where $k \geq 0$ and $T_{\mathrm{s}}$ are the sample number and the sampling period, respectively). Moreover, the time function and its Laplace transform are denoted by the same notation, such as $P(t)$ and $P(s)$.

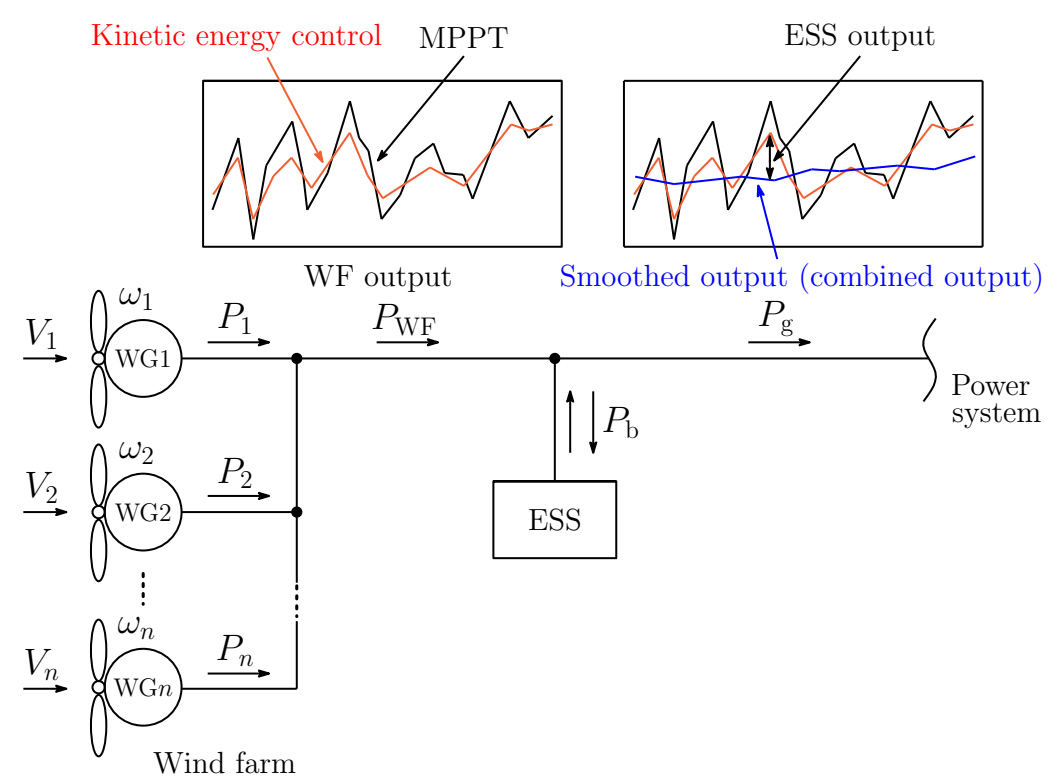

Figure 1. System configuration.

\subsection{Wind Turbine Model}

The output characteristics of the wind turbine [22,23] are expressed by:

$$
\begin{aligned}
P_{i}= & \frac{1}{2} \rho \pi R^{2} V_{i}^{3} C_{\mathrm{p}}(\beta, \lambda), \\
C_{\mathrm{p}}(\lambda, \beta)=0.5176 & \left(\frac{116}{\lambda_{\mathrm{i}}}-0.4 \beta-5\right) \mathrm{e}^{\frac{-21}{\lambda_{\mathrm{i}}}}+0.0068 \lambda, \\
\frac{1}{\lambda_{\mathrm{i}}} & =\frac{1}{\lambda+0.08 \beta}-\frac{0.035}{\beta^{3}+1}, \\
\lambda & =\frac{\omega_{i} R}{V_{i}} \\
\frac{\mathrm{d} \omega_{i \mathrm{pu}}}{\mathrm{d} t} & =\frac{1}{2 H}\left(T_{\mathrm{m} i}-T_{\mathrm{e} i}\right),
\end{aligned}
$$

where $\rho\left(=1.225 \mathrm{~kg} / \mathrm{m}^{3}\right)$ is the air-density, $R$ is the radius of rotor blade, $\lambda$ is the tip speed ratio, $\beta$ is the blade pitch angle, $C_{\mathrm{p}}$ is the power coefficient, $H$ is the inertia constant of the WG, $T_{\mathrm{m} i}(i=1,2, \cdots, n)$ is the mechanical torque, and $T_{\mathrm{e} i}(i=1,2, \cdots, n)$ is the electrical torque. The subscripts pu denote the per-unit. In variable speed wind turbines, high efficiency operation is achieved by MPPT, which keeps $C_{\mathrm{p}}(\lambda, \beta)$ maximum. Figure 2 shows the $C_{\mathrm{p}}-\lambda$ curve of the wind turbine. From Figure 2 , the maximum 
power coefficient $C_{\mathrm{p}}^{\mathrm{opt}}=0.48$ and the optimum tip speed ratio $\lambda^{\mathrm{opt}}=8.1$ ( $\beta$ is kept at zero) are known. As shown in [22,23], the MPPT output reference $P_{i}^{\text {mppt }}$ and its per-unit are given by

$$
\begin{aligned}
P_{i}^{\mathrm{mppt}} & =\frac{1}{2} \rho \pi R^{2}\left(\frac{R}{\lambda^{\mathrm{opt}}}\right)^{3} C_{\mathrm{p}}^{\mathrm{opt}} \omega_{i}^{3}[\mathrm{~W}], \\
P_{i \mathrm{pu}}^{\mathrm{mppt}} & =\frac{P_{i}^{\mathrm{mppt}}}{P_{\mathrm{n}}}=\omega_{i \mathrm{pu}}^{3}[\text { p.u.] }
\end{aligned}
$$

respectively. In (7), the rated output $P_{\mathrm{n}}$ of the WG is $\frac{1}{2} \rho \pi R^{2}\left(\frac{R}{\lambda_{\text {opt }}}\right)^{3} C_{\mathrm{p}}^{\mathrm{opt}}\left(\omega_{\text {in }}\right)^{3}$ where $\omega_{\text {in }}$ is the rated mechanical rotor angular frequency. It is clear that the MPPT reference is calculated without measuring the wind speed. Note that a pitch angle control system [24] is used in order to prevent the wind turbine from rotating faster than the rated speed.

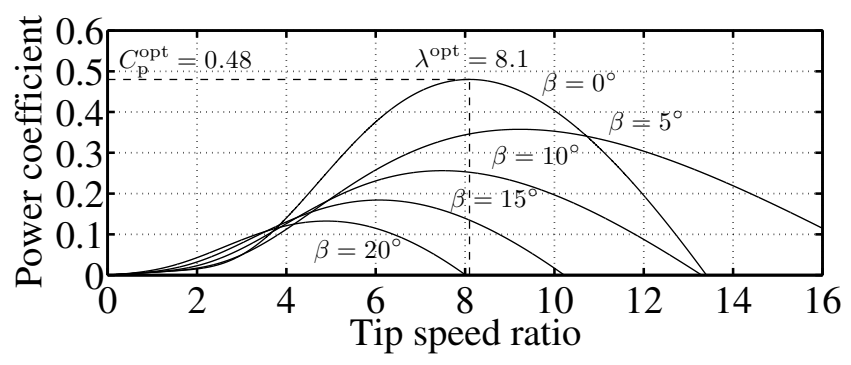

Figure 2. $C_{\mathrm{p}}-\lambda$ curve of wind turbine.

\subsection{ESS Control System}

The ESS control system that was proposed in [14] is briefly described in this subsection. Figure 3 shows the ESS configuration (the block diagram of the ESS in Figure 1). $P_{\text {loss }}$ is the charge/discharge loss of the ESS, as given by

$$
P_{\text {loss }}(t)= \begin{cases}(1-\eta) \cdot P_{\mathbf{b}}(t) & \left(P_{\mathbf{b}}(t)>0\right) \\ \left(1-\frac{1}{\eta}\right) \cdot P_{\mathbf{b}}(t) & \left(P_{\mathbf{b}}(t)<0\right)\end{cases}
$$

where $\eta$ is the charge/discharge efficiency of the ESS. $E$ denotes the remaining energy of the ESS that is calculated by integrating $P_{\mathrm{b}}-P_{\text {loss }}$. In Figure 3, the block diagram in the dashed frame shows the SOC-FB control [8], which regulates the state-of-charge (SOC) to its reference, and $A$ is the SOC-FB gain. A controller $K(s)$ that removes short-period components from the WF output is given by

$$
K(s)=K_{\mathrm{p}} \cdot G_{\mathrm{hpf}}(s), \quad G_{\mathrm{hpf}}(s)=\frac{s^{2}}{s^{2}+a_{1} s+a_{0}}
$$

where $a_{0}, a_{1}>0, K_{\mathrm{p}}\left(0<K_{\mathrm{p}} \leq 1\right)$ is a constant gain and $G_{\mathrm{hpf}}(s)$ is a second-order high-pass filter. The WF output are divided into short and long period components $P_{\mathrm{WF}}^{\mathrm{s}}$ and $P_{\mathrm{WF}}^{\mathrm{l}}$. Specifically, $P_{\mathrm{WF}}^{\mathrm{s}}=s^{2} P_{\mathrm{WF}}(s) /\left(s^{2}+a_{1} s+a_{0}\right), P_{\mathrm{WF}}^{\mathrm{l}}=\left(a_{1} s+a_{0}\right) P_{\mathrm{WF}}(s) /\left(s^{2}+a_{1} s+a_{0}\right)$ and $P_{\mathrm{WF}}(s)=P_{\mathrm{WF}}^{\mathrm{s}}+P_{\mathrm{WF}}^{\mathrm{l}}$. Thus, the combined output is obtained by

$$
P_{\mathrm{g}}(s)=\left(1-K_{\mathrm{p}}\right) \cdot P_{\mathrm{WF}}^{\mathrm{s}}+P_{\mathrm{WF}}^{\mathrm{l}} \cdot
$$

It is clear that the short-period component is reduced by a factor of $\left(1-K_{\mathrm{p}}\right)$ and the long-period component is directly supplied to the power system. Moreover, the ESS output is given by

$$
P_{\mathrm{b}}(t) \approx K_{\mathrm{p}} \cdot P_{\mathrm{WF}}^{\mathrm{s}}
$$


Consequently, the controller proposed in [14] can reduce the required rated power of the ESS by a factor of $K_{\mathrm{p}}$.

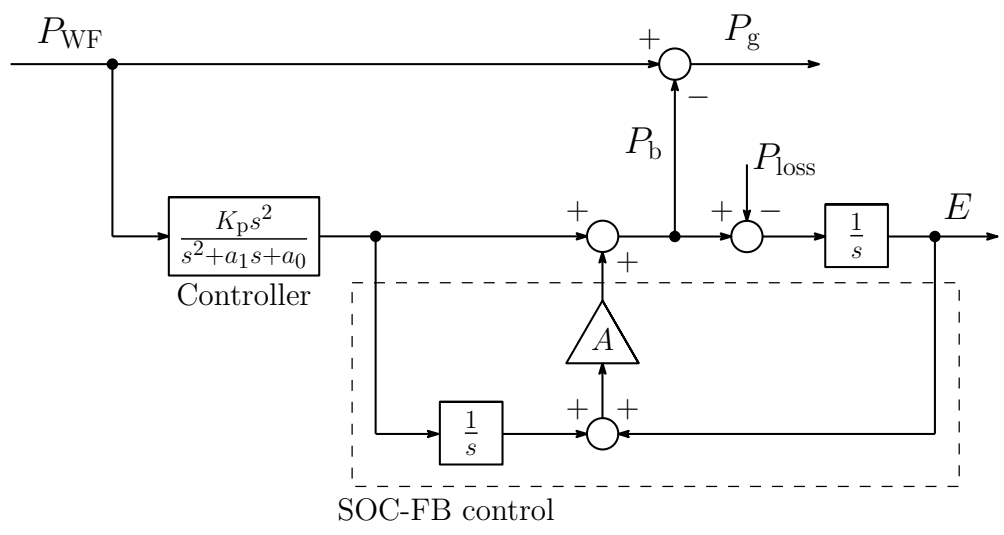

Figure 3. ESS control system.

\subsection{Fluctuation of Combined Output and Technical Requirement}

In this paper, the cost of the system that is composed of the ESS and the WF operated by KE control is investigated based on the following technical requirement $[6,7,14]$.

- The maximum power change per minute is within $10 \%$ of the WF power rating.

The combined output fluctuation $\Delta F_{\mathrm{g}}$ in a 1-min window is defined as

$$
\Delta F_{\mathrm{g}}(t)=\frac{\max _{t-1-\min \leq \tau \leq t} P_{\mathrm{g}}(\tau)-\min _{t-1-\min \leq \tau \leq t} P_{\mathrm{g}}(\tau)}{P_{\mathrm{WFn}}},
$$

where $P_{\mathrm{WFn}}$ is the rated WF output. Therefore, the WF output has to be mitigated in order to satisfy $\Delta F_{\mathrm{g}}(t) \leq 10 \%$.

\section{Kinetic Energy Control}

As mentioned in Section 1, the KE control has a trade-off between smoothing the WG output and the generating efficiency. First, this section explains the standard KE control using MA. Subsequently, an optimized KE control considering the trade-off is proposed to improve the cost efficiency of KE control. Although a KE control is applied to a single WG in general, we generalize the KE control for the WF.

\subsection{Standard Moving Average Kinetic Energy Control}

A KE control can be achieved by making the WG output follow its reference $P_{i p u}^{\text {ref }}(i=1,2, \ldots, n)$ without the short-period components. Figure 4 shows the WGs with the MA KE control [18]. The shortperiod components of the WF output $\Delta P_{\mathrm{WFpu}}$ are smoothed out by the MA that is defined by

$$
P_{\mathrm{WFpu}}^{\mathrm{MA}}[k]=\frac{1}{m} \sum_{i=1}^{m} P_{\mathrm{WFpu}}[k]
$$

where $P_{\mathrm{WFpu}}^{\mathrm{MA}}$ is MA of $P_{\mathrm{WFpu}}$ in the last $m$ steps. Subsequently, $\Delta P_{\mathrm{WFpu}}\left(=P_{\mathrm{WFpu}}-P_{\mathrm{WFpu}}^{\mathrm{MA}}\right)$ is allocated to each $W G$, as follows

$$
\Delta P_{i \mathrm{pu}}=\frac{P_{i \mathrm{pu}}^{\mathrm{mppt}}}{P_{\mathrm{WFpu}}^{\mathrm{mppt}}} \cdot \Delta P_{\mathrm{WFpu}}
$$


where $\Delta P_{i p u}(i=1,2, \cdots, n)$ is the fluctuation component to be compensated by WG and $P_{\mathrm{WFpu}}^{\mathrm{mppt}}=\sum_{i=1}^{n} P_{i \mathrm{pu}}^{\mathrm{mppt}}$. The KE used to smooth the WF output increases by allocating the fluctuation components based on (14), because a WG with a higher rotational speed can release the KE more than other WGs with a low rotational speed. The generator efficiency can be increased by applying this allocation method to the method that was proposed in [18]. Finally, the WG reference output is given by

$$
P_{i \mathrm{pu}}^{\mathrm{ref}}=P_{i \mathrm{pu}}^{\mathrm{mppt}}-f\left(\omega_{i \mathrm{pu}}\right) \cdot \Delta P_{i \mathrm{pu}}
$$

where $f\left(\omega_{i \mathrm{pu}}\right)$ is given by

$$
f\left(\omega_{i \mathrm{pu}}\right)= \begin{cases}1 & \left(0.5<\omega_{i \mathrm{pu}}\right) \\ \left(10 \omega_{i \mathrm{pu}}-4\right) & \left(0.4 \leq \omega_{i \mathrm{pu}} \leq 0.5\right), \\ 0 & \left(\omega_{i \mathrm{pu}}<0.4\right) .\end{cases}
$$

The role of $f\left(\omega_{i \mathrm{pu}}\right)$ is to prevent the WG with low rotational speed from releasing excessive energy [18]. In this paper, the dynamics of the back-to-back converter in the WG is ignored to shorten the simulation time, because it is known that this does not affect the analysis, except for transient analysis, such as voltage dips [25]. Namely, this paper assumes $P_{i}^{\text {ref }} \approx P_{i}$.

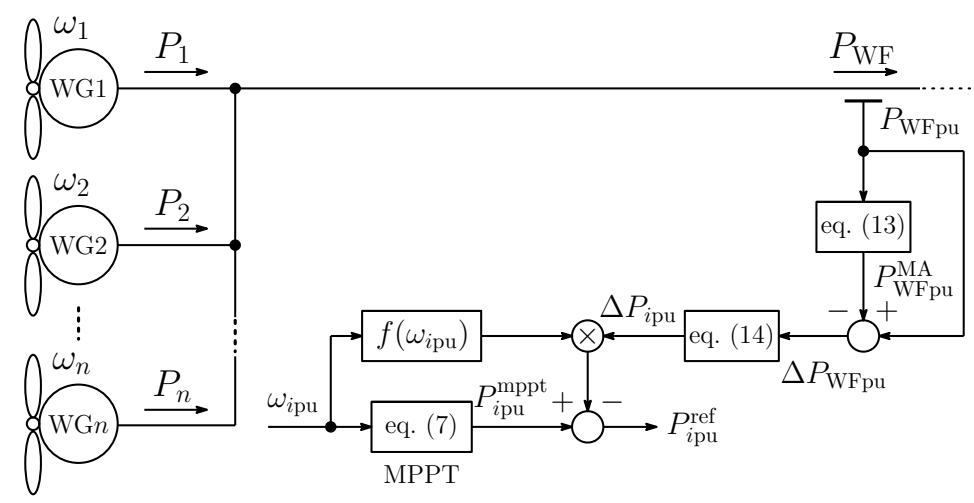

Figure 4. The standard moving average kinetic energy control.

\subsection{Optimal Kinetic Energy Control}

Figure 5 shows the WGs with the proposed optimal KE control. To consider the trade-off between the WG output smoothing and the generating efficiency, we optimize the WG reference by the following optimization problem:

$$
P_{i \mathrm{pu}}^{\mathrm{ref}}=\arg \min J\left(P_{i \mathrm{pu}}^{\mathrm{mppt}}, f\left(\omega_{i \mathrm{pu}}\right) \cdot \Delta P_{i \mathrm{pu}}\right),
$$

where

$$
J\left(P_{i \mathrm{pu}}^{\mathrm{mppt}}, f\left(\omega_{i \mathrm{pu}}\right) \cdot \Delta P_{i \mathrm{pu}}\right)=\left(P_{i \mathrm{pu}}^{\mathrm{mppt}}-P_{i \mathrm{pu}}^{\mathrm{ref}}\right)^{2}+q\left(\left(P_{i \mathrm{pu}}^{\mathrm{mppt}}-f\left(\omega_{i \mathrm{pu}}\right) \cdot \Delta P_{i \mathrm{pu}}\right)-P_{i \mathrm{pu}}^{\mathrm{ref}}\right)^{2} .
$$

The roles of the first term and the second term in (18) keeps the generating efficiency and smooths the WF output, respectively. It is clear that the WF can be optimally operated, handling the trade-off, when each WG output is regulated to its reference $P_{i p u}^{\text {ref }}$ that is obtained from (17). In (18), $q$ is a nonlinear weight that is given by

$$
q=K_{\mathrm{q}}\left(\left|\Delta P_{\mathrm{WFpu}}\right|\right)^{\alpha},
$$


where $K_{\mathrm{q}} \geq 0$ and the natural number $\alpha$ are weight and exponent weight, respectively. Weight $q$ becomes small when $\Delta P_{\mathrm{WFpu}}$ approaches zero. It implies that the generating efficiency increases when the fluctuation of the WF output is small, because the second term in (18) is low. Figure 6 shows the relation between $\Delta P_{\mathrm{WFpu}}$ and $q\left(K_{q}, \alpha\right)$. Although it is difficult to find the best values of $K_{\mathrm{q}}$ and $\alpha$ analytically, these weights can be determined based on the technical requirement and Figure 6 . For example, when $\Delta P_{\text {WFpu }} \geq 0.1$ p.u., $q$ has to be large in order to guarantee the technical requirement $\Delta F_{\mathrm{g}}(t) \leq 10 \%$. Therefore, $K_{\mathrm{q}}$ and $\alpha$ in (19) should be determined to satisfy the condition that $q$ is large when $\Delta P_{\mathrm{WFpu}} \geq 0.1$ p.u.

The solution $P_{i \mathrm{pu}}^{\text {ref }}$ of (17) can be easily obtained by solving $\frac{\mathrm{d} J}{\mathrm{~d} P_{i \mathrm{pu}}^{\text {ref }}}=0$ because (18) is a convex function of $P_{i p u}^{\text {ref }}$. The solution is

$$
P_{i \mathrm{pu}}^{\mathrm{ref}}=\frac{P_{\mathrm{ipu}}^{\mathrm{mppt}}+q\left(P_{i \mathrm{pu}}^{\mathrm{mppt}}-f\left(\omega_{i \mathrm{pu}}\right) \cdot \Delta P_{i \mathrm{pu}}\right)}{1+q} .
$$

The calculation time of (20) is short because (20) is a purely algebraic calculation. Therefore, this method does not require any special software (CPLEX and Gurobi, etc.) or numerical optimization (genetic algorithm and particle swarm optimization, etc.).

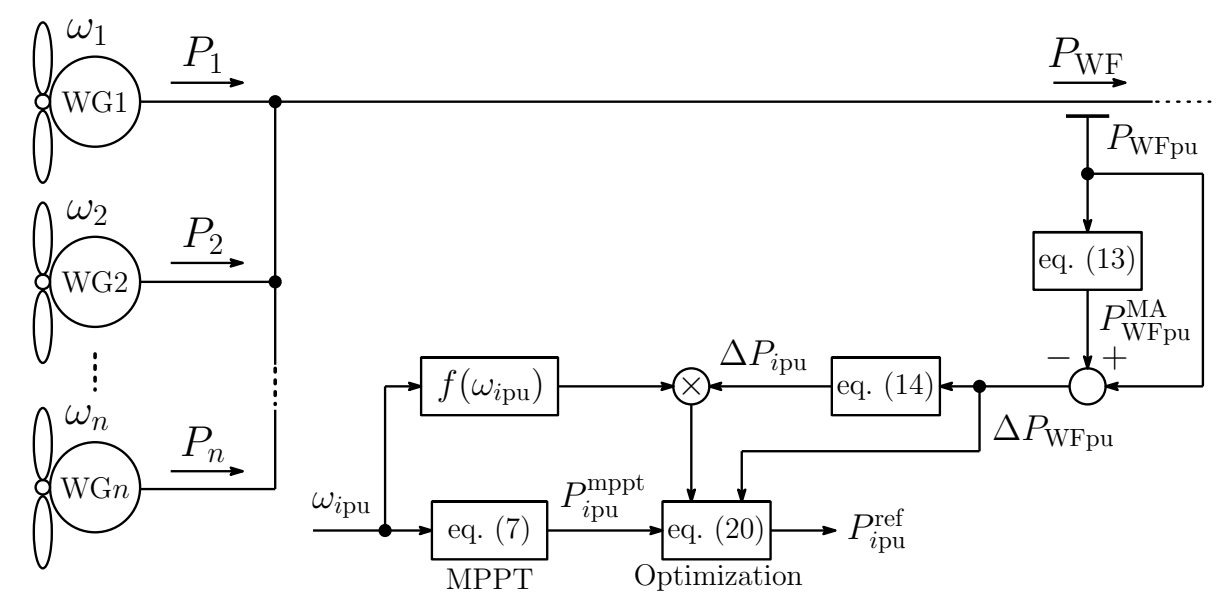

Figure 5. Optimal kinetic energy control.

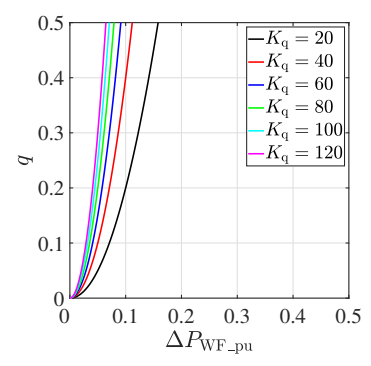

(a) $\alpha=2$

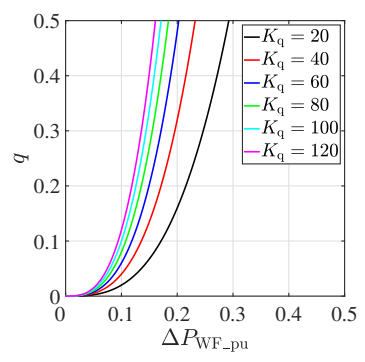

(b) $\alpha=3$

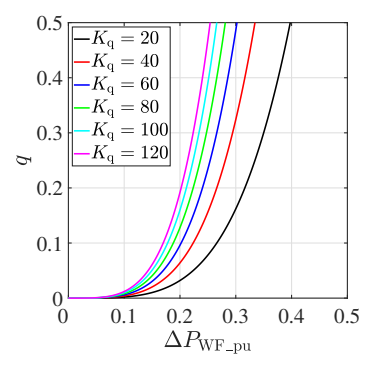

(c) $\alpha=4$

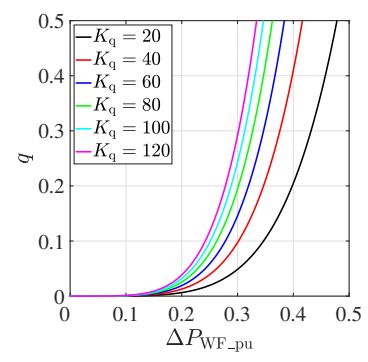

(d) $\alpha=5$

Figure 6. $q$ vs. $\Delta P_{\mathrm{WFpu}}$.

\section{Cost Calculation Method}

This section explains the method for estimating the cost of the system that is composed of the ESS and the WF operated by KE control. The cost during the lifespan of a WG is investigated in this analysis. 
We define the installation cost of WF, ESS, an opportunity loss of WF, ESS, and cost of power converter system (PCS) of the battery in order to calculate the total cost of the system composed of the ESS and the WF operated by KE control, as follows:

Installation cost of WF:

$$
C_{\mathrm{WF}}^{\mathrm{I}}[\mathrm{JPY}]=n \times P_{\mathrm{n}}[\mathrm{kW}] \times \mathrm{WG} \text { price }[J P Y / \mathrm{kW}],
$$

Opportunity loss of WF:

$$
C_{\mathrm{WF}}^{\mathrm{O}}[\mathrm{JPY}]=E_{\mathrm{WF}}^{\text {loss }}[\mathrm{kWh} / \mathrm{h}] \times \text { Lifespan of WG }[\mathrm{h}] \times \text { Wind power price }[\mathrm{JPY} / \mathrm{kWh}],
$$

Installation cost of ESS:

$$
C_{\mathrm{ESS}}^{\mathrm{I}}[\mathrm{JPY}]=\frac{\text { Rated capacity }[\mathrm{kWh}] \times \text { Battery price }[\mathrm{JPY} / \mathrm{kWh}]}{\text { Battery lifespan }[\mathrm{h}]} \times \text { Lifespan of WG }[\mathrm{h}],
$$

Opportunity loss of ESS:

$$
C_{\mathrm{ESS}}^{\mathrm{O}}[\mathrm{JPY}]=E_{\mathrm{ESS}}^{\text {loss }}[\mathrm{kWh} / \mathrm{h}] \times \text { Lifespan of WG }[\mathrm{h}] \times \text { Wind power price }[\mathrm{JPY} / \mathrm{kWh}] .
$$

Cost of PCS:

$$
C_{\mathrm{PCS}}[\mathrm{JPY}]=\mathrm{PCS} \text { price }[\mathrm{JPY} / \mathrm{kW}] \times \text { Rated power of ESS }[\mathrm{kW}] .
$$

For simplicity, the maintenance cost is neglected. The energy loss $E_{\mathrm{WF}}^{\text {loss }}$ is defined by $\int_{0}^{1} \mathrm{~h}\left[P_{\mathrm{WF}}^{\mathrm{MPT}}(t)-\right.$ $P_{\mathrm{WF}}^{\mathrm{MA}}(t)\left(\right.$ or $\left.\left.P_{\mathrm{WF}}^{\mathrm{opt}}(t)\right)\right] \mathrm{d} t$ which implies the energy lost by the KE control. The rated capacity of the ESS $[\mathrm{kWh}]$ is determined by the rated power of the ESS that was obtained by the simulations. Although the cost of an ESS is determined by the rated capacity, it is constrained by the rated power of the ESS through the so-called C-rate [14,26]. The C-rate is given by

$$
\text { C-rate }=\frac{\text { Rated power of ESS }[\mathrm{kW}]}{\text { Rated Capacity of ESS }[\mathrm{kWh}]} .
$$

In (24), E ESS is the integral of the charge/discharge loss $\int_{0}^{1 \mathrm{~h}} P_{\text {loss }}(t) \mathrm{d} t$. Battery lifespan depends on the calendar life $L^{\mathrm{cal}}$ and cycle life $L^{\mathrm{cyc}}$. $L^{\mathrm{cal}}$ is the lifespan due to the deterioration over time when the ESS does not charge/discharge. By contrast, $L^{\text {cyc }}$ is the lifespan due to the deterioration when ESS charges/discharges and it is influenced by the number of charge/discharge and the depth of discharge (DOD) [27]. Figure 7 shows the relation between the number of cycles (charge/discharge) and the DOD [28]. $L^{\text {cyc }}$ can be estimated by the rain-flow counting $[29,30]$ and Figure 7 from the time responses obtained by simulation. Refer to $[29,30]$ for the detailed calculation method of $L^{\text {cyc }}$. The battery lifespan is calculated by

$$
\text { Battery lifespan } \approx \min \left\{L^{\mathrm{cal}}, L^{\mathrm{cyc}}\right\} .
$$

The total cost of the system is calculated by

$$
\text { Total cost }=C_{\mathrm{WF}}^{\mathrm{I}}+C_{\mathrm{WF}}^{\mathrm{O}}+C_{\mathrm{ESS}}^{\mathrm{I}}+C_{\mathrm{ESS}}^{\mathrm{O}}+C_{\mathrm{PCS}} .
$$

From (28), the profit obtained in the WG lifespan can be calculated by

$$
\begin{gathered}
\text { profit }=\int_{0}^{1 \mathrm{~h}} P_{\mathrm{WF}}^{\mathrm{MPPT}}(t) \mathrm{d} t[\mathrm{kWh} / \mathrm{h}] \times \text { Lifespan of WG }[\mathrm{h}] \times \text { Wind power price }[\mathrm{JPY} / \mathrm{kWh}] \\
- \text { Total cost }[J P Y]
\end{gathered}
$$


As a result, we can validate the system that is composed of the ESS and the WF operated by KE control based on (28) and (29).

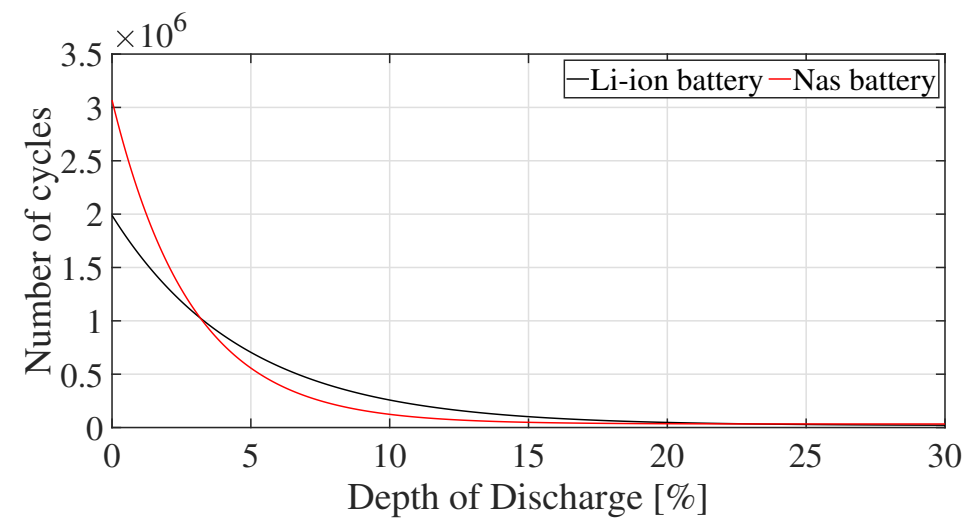

Figure 7. Life cycles vs. depth of discharge.

One hour simulation is conducted under typical wind condition to compute the generated energy and energy loss. Subsequently, all costs/profits are evaluated under the assumption that wind condition represents the typical situation.

Remark 1. The cost evaluation is of course rather rough because of the limitation of available wind data. Its precision can be improved by replacing $E_{\mathrm{WF}}^{\mathrm{loss}}, E_{\mathrm{ESS}}^{\text {loss }} \int_{0}^{1} \mathrm{~h} P_{\mathrm{WF}}^{\mathrm{MPPT}} \mathrm{d} t, L^{\text {cyc }}$ by the corresponding per hour averages if the wind data is available.

\section{Simulations and Discussions}

A comparative simulation is performed between the proposed systems and the conventional system composed of ESS and WF operated by MPPT control in order to validate the proposed systems composed of ESS and WF with KE control (the MA KE or the optimal KE control) based on the cost. We investigate two types of ESS: Li-ion and NaS battery. The real wind speed data (Five typical scenarios are selected for the analysis.) was measured at a WF in Hokkaido, Japan. These data were sampled every $3 \mathrm{~s}$ and their average and standard deviation (SD) are listed in Table 2. One Scenario is shown Figure 8. The costs and profits can be estimated accurately based on the simulation results that were obtained through enough wind data measured in four seasons. However, we do not have the data. As an alternative, we conduct one hour simulation based on five typical scenarios. The analysis condition, the parameters of ESSs and the controller parameters of WG and ESS are listed in Tables 3-5. Currently, the wind power price is $16 \mathrm{JPY} / \mathrm{kWh}$ in Japan [31]. However, we calculate the cost of the system based on the wind power price of $8 \mathrm{JPY} / \mathrm{kWh}$, because the price will be cheaper in the near future. The price of batteries and the PCS are slightly different makers. The price was determined based on $[10,26,32,33]$. In addition, the efficiency of the li-ion and NaS battery is within $85 \%$ to $95 \%$, respectively. Therefore, it is assumed that these batteries have the same efficiency in this analysis. We set the number of steps for MA as 10 times larger than a 1-min. window in the technical requirement $\left(1200 \cdot T_{\mathrm{s}}=600 \mathrm{~s}\right) . K_{\mathrm{q}}$ and $\alpha$ are determined using Figure 6 , so that $q$ becomes large when $\Delta P_{\mathrm{WF}-\mathrm{pu}} \geq 0.1$. In the simulation, $K_{\mathrm{p}}$ is determined by scenario simulations in order to ensure the technical requirement. Note that $K_{\mathrm{p}}$ of the conventional system is the highest among the systems, because the conventional system does not have the KE control. The parameters for $a_{0}$ and $a_{1}$ are the same as [14].

The simulation was performed on MATLAB/Simulink 2019b and the simulation period was $3600 \mathrm{~s}$. The time responses for scenarios 2 to 5 are omitted. 
Table 2. Characteristics of wind data.

\begin{tabular}{rrrrrrrrrrr}
\hline & \multicolumn{3}{c}{ Scenario 1 } & \multicolumn{2}{c}{ Scenario 2 } & \multicolumn{2}{c}{ Scenario 3 } & \multicolumn{2}{c}{ Scenario 4 } & \multicolumn{2}{c}{ Scenario 5 } \\
\hline & Avg. & SD & Avg. & SD & Avg. & SD & Avg. & SD & Avg. & SD \\
\hline$V_{1}$ & 7.30 & 1.36 & 8.45 & 1.61 & 8.34 & 1.72 & 10.4 & 2.15 & 10.4 & 2.15 \\
$V_{2}$ & 9.59 & 1.81 & 8.93 & 1.78 & 8.66 & 1.85 & 8.09 & 1.79 & 8.09 & 1.79 \\
$V_{3}$ & 8.36 & 1.84 & 8.90 & 1.37 & 6.51 & 0.95 & 8.51 & 1.18 & 8.51 & 1.18 \\
$V_{4}$ & 10.13 & 2.03 & 7.62 & 1.68 & 11.12 & 1.83 & 10.40 & 1.55 & 10.39 & 1.55 \\
$V_{5}$ & 10.34 & 1.60 & 10.11 & 1.60 & 9.96 & 1.59 & 4.82 & 0.77 & 4.82 & 0.77 \\
$V_{6}$ & 5.26 & 1.99 & 5.16 & 2.19 & 4.56 & 1.93 & 14.55 & 1.92 & 14.55 & 1.93 \\
$V_{7}$ & 8.02 & 1.79 & 10.96 & 1.74 & 8.96 & 2.27 & 9.82 & 1.70 & 9.82 & 1.70 \\
$V_{8}$ & 6.46 & 2.32 & 9.60 & 2.08 & 6.35 & 2.35 & 8.68 & 2.00 & 8.68 & 2.00 \\
$V_{9}$ & 9.33 & 2.02 & 10.64 & 1.83 & 9.85 & 2.53 & 7.02 & 1.44 & 7.02 & 1.44 \\
$V_{10}$ & 7.00 & 2.56 & 4.87 & 2.12 & 6.35 & 2.33 & 7.15 & 1.44 & 7.15 & 1.44 \\
$V_{11}$ & 11.99 & 1.15 & 15.47 & 1.17 & 11.5 & 0.99 & 11.97 & 2.61 & 11.97 & 2.61 \\
$V_{12}$ & 13.68 & 1.92 & 13.54 & 2.16 & 14.55 & 1.98 & 9.12 & 1.48 & 9.12 & 1.48 \\
$V_{13}$ & 15.01 & 1.09 & 15.39 & 2.49 & 14.68 & 1.54 & 12.10 & 2.16 & 12.10 & 2.16 \\
$V_{14}$ & 15.45 & 1.72 & 11.77 & 1.78 & 15.6 & 1.84 & 7.05 & 1.50 & 7.05 & 1.50 \\
$V_{15}$ & 19.48 & 1.38 & 18.66 & 1.34 & 19.45 & 1.20 & 10.42 & 1.52 & 10.42 & 1.52 \\
\hline
\end{tabular}

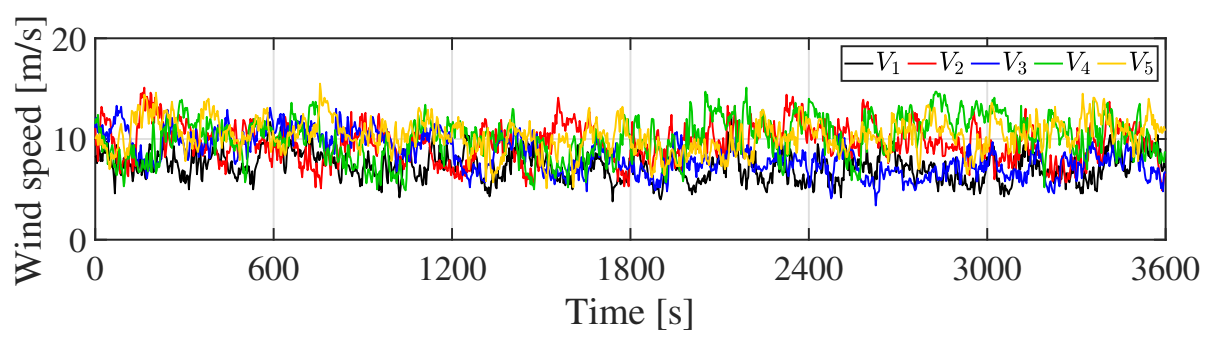

(a) $V_{1}, V_{2}, V_{3}, V_{4}$ and $V_{5}$.

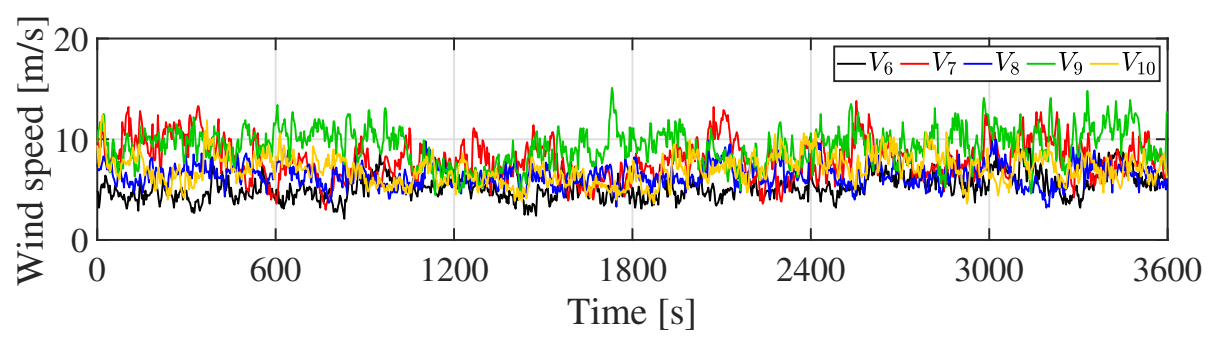

(b) $V_{6}, V_{7}, V_{8}, V_{9}$ and $V_{10}$.

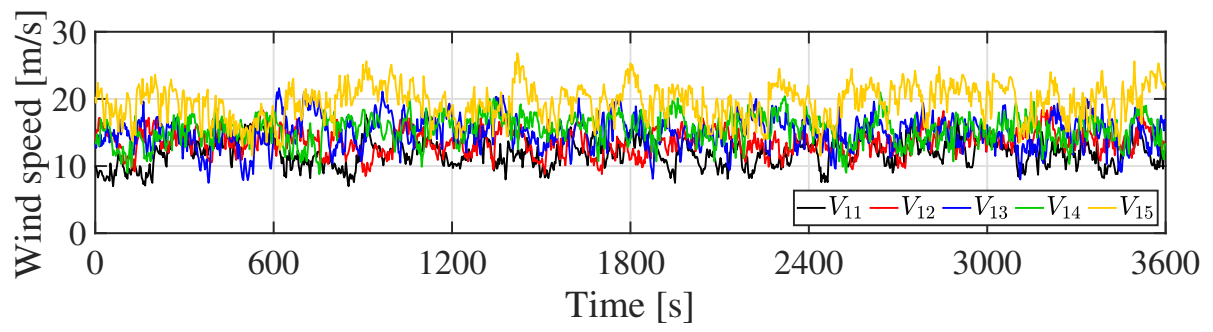

(c) $V_{11}, V_{12}, V_{13}, V_{14}$ and $V_{15}$.

Figure 8. Wind speed (Scenario 1). 
Table 3. Analysis condition.

\begin{tabular}{lc}
\hline Rated power of WG [MW] & 5 \\
Rated wind speed [m/s] & 12 \\
Inertia constant $H$ of WG [s] & 5.05 \\
Number of WG & 15 \\
Lifespan of WG [y] & 20 \\
Wind power price [JPY/kWh] & 8 \\
$C_{\mathrm{WF}}^{\mathrm{I}}$ [100 Million JPY] & 150 \\
\hline
\end{tabular}

Table 4. Parameters of energy storage systems (ESSs).

\begin{tabular}{lcc}
\hline & Li-Ion Battery & NaS Battery \\
\hline C-rate & 3 & 0.13 \\
Price [JPY $/ \mathrm{kWh}]$ & 200,000 & 25,000 \\
Efficiency $\eta[\%]$ & 85 & 85 \\
$L^{\text {cal }}[\mathrm{y}]$ & 10 & 15 \\
PCS price $[\mathrm{JPY} / \mathrm{kW}]$ & 28,800 & 28,800 \\
\hline
\end{tabular}

Table 5. Controller parameters of wind generator (WG) and ESS.

\begin{tabular}{lccc}
\hline & Con. (MPPT) & Pro. (MA) & Pro. (Opt.) \\
\hline Sampling period [s] & 0.5 & 0.5 & 0.5 \\
Number of Steps for MA & - & 1200 & 1200 \\
$K_{\mathrm{q}}$ & - & 120 & - \\
$\alpha$ & - & 5 & - \\
$K_{\mathrm{p}}$ & 0.65 & 0.5 & 0.5 \\
$a_{0}$ & $9 \times 10^{-6}$ & $9 \times 10^{-6}$ & $9 \times 10^{-6}$ \\
$a_{1}$ & $6 \times 10^{-3}$ & $6 \times 10^{-3}$ & $6 \times 10^{-3}$ \\
$A$ & 1 & 1 & 1 \\
\hline
\end{tabular}

\subsection{Simulations Results}

Figure 9 shows the WF output. It is clear that the WF output is smoothed by the KE control. Especially, the proposed optimal KE control mitigates the WF output only when the fluctuation becomes large. Therefore, the generating efficiency of WF with the optimal KE controller is kept higher than that of the MA KE controller. By contrast, $L^{\mathrm{cyc}}$ can be large, and the charge/discharge loss of ESS is reduced by the MA KE control, because the stress of ESS is reduced. Figure 10 shows the ESS output. The peak of ESS output in the proposed systems is smaller than that in the conventional system. It implies that the technical requirement can be satisfied by an ESS with smaller rated power (small rated capacity). Figure 11 shows the combined output. It can be seen from Figures 9 and 11 that the fluctuation of WF output is smoothed by the ESS. Although the KE control cannot satisfy the technical requirement by itself, as shown in Figure 12, the proposed system with the KE control and the ESS guarantees the requirement (Figure 13). Figures 14 and 15 show the SOC of Li-ion battery and $\mathrm{NaS}$ battery, respectively. The SOC of the ESS in the proposed/conventional systems is maintained within the proper range. The fluctuation of the SOC of Li-ion battery is larger than that of NaS battery, because the C-rate of Li-ion battery is bigger than that of the NaS battery, although these batteries have the same rated power. Table 6 summarizes the simulation results. Rated power (rated capacity) of ESS is estimated from Table 6. The rated output power of the ESS in the proposed systems are approximately $45 \%$ less than that of the ESS in the conventional system. It is evident from these results that the technical requirement $\Delta F_{\mathrm{g}}(t) \leq 10 \%$ is satisfied while maintaining a lower charge/discharge loss of the ESS while using the KE control. Table 6 lists the SD of $P_{\mathrm{WF}}$ and $P_{\mathrm{g}}$. These values is related to power quality, such as frequency in the power system. It is clear that the WF with KE control can mitigate not only 1-Min. fluctuation of $P_{\mathrm{WF}}\left(P_{\mathrm{g}}\right)$ but also SD of WF output $P_{\mathrm{WF}}\left(P_{\mathrm{g}}\right)$ without increasing 
the rated power of ESS. Moreover, the proposed optimal KE control can reduce the $E_{\mathrm{WF}}^{\text {loss }}$, not requiring ESS with a high rated power. However, the Li-ion battery lifespan of the proposed system with the optimal KE controller is shorter than that with the MA KE controller because the MA KE controller removes the fluctuation of the WF output, regardless of whether the WF has large fluctuations or not. Therefore, the cycle life of the Li-ion battery in the proposed system with the MA KE control is longer than the proposed system with the optimal KE control. Note that the Li-ion battery lifespan of the ESS in the conventional system is larger than that of the proposed systems, because the ESS has large rated capacity. For the same reason, the lifespan of the NaS battery is determined by the calendar life, since the C-rate of the NaS battery is small.

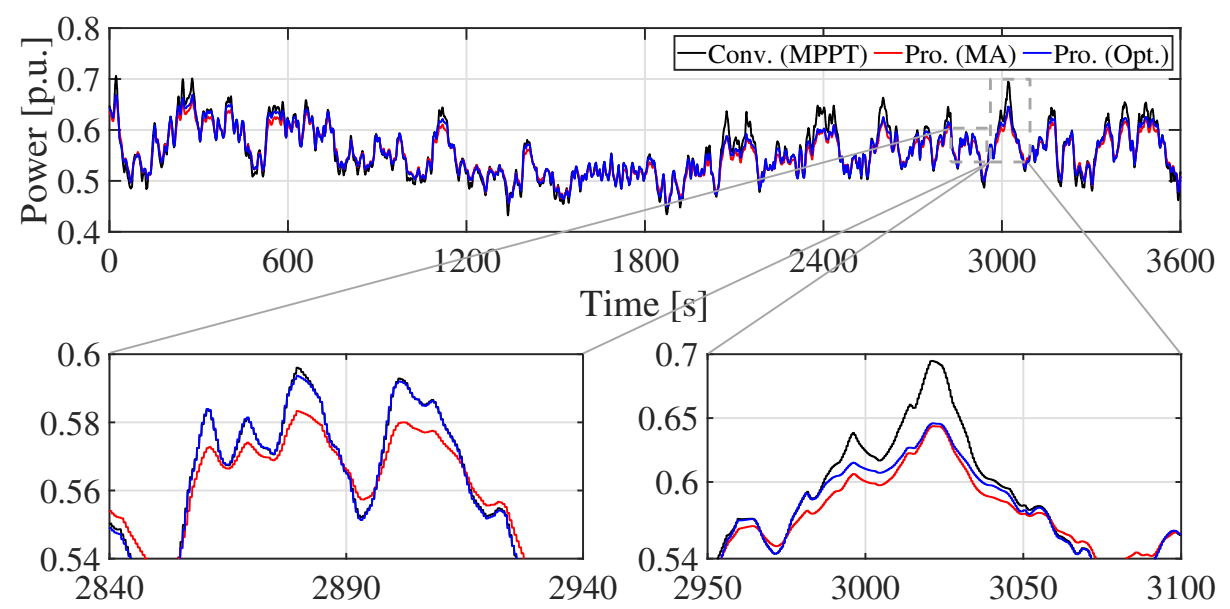

Figure 9. Wind farm (WF) output (Scenario 1).

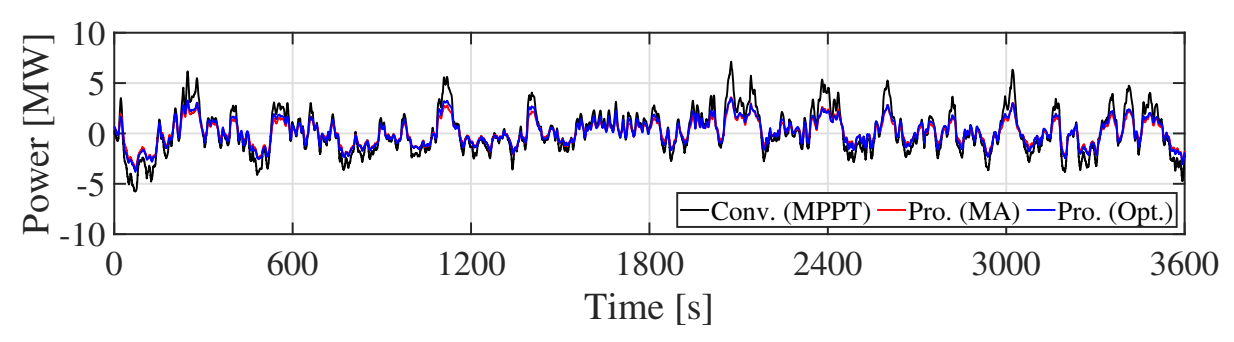

Figure 10. ESS output (Scenario 1).

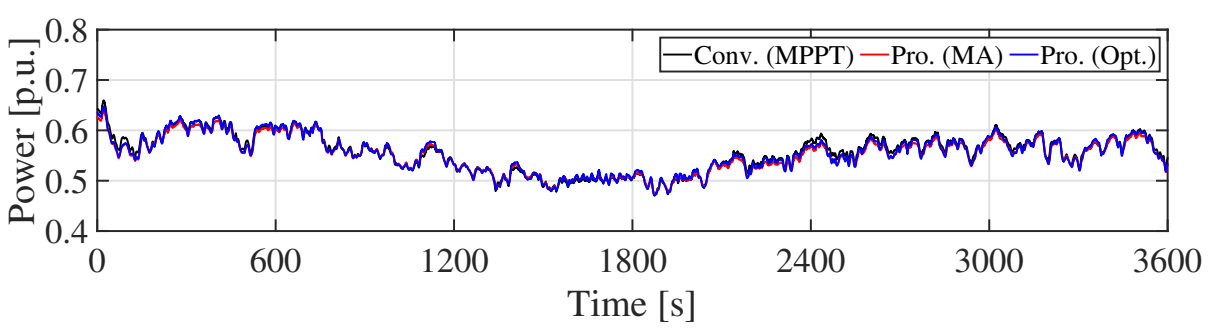

Figure 11. Combined output (Scenario 1). 


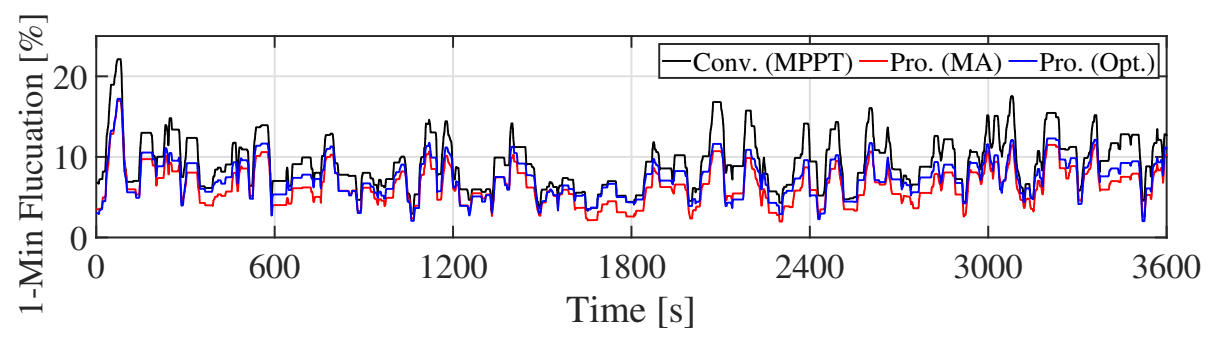

Figure 12. Fluctuation of WF output (Scenario 1).

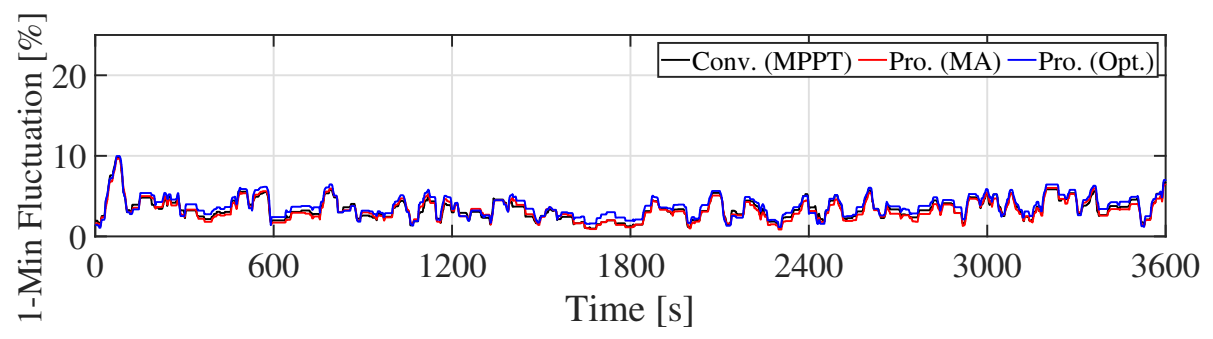

Figure 13. Fluctuation of combined output (Scenario 1).

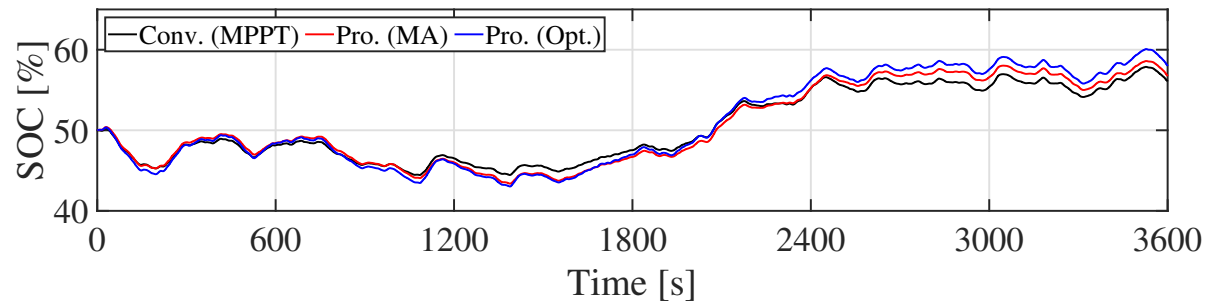

Figure 14. SOC of the Li-ion battery (Scenario 1).

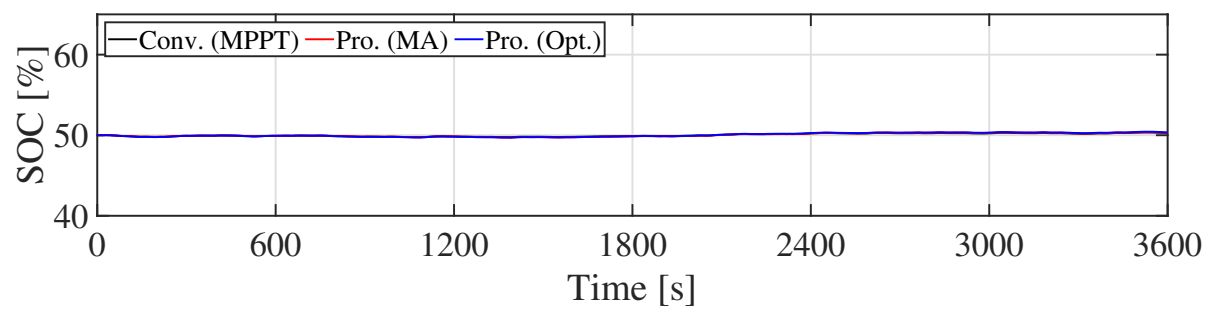

Figure 15. SOC of the NaS battery (Scenario 1). 
Table 6. Simulation results.

\begin{tabular}{|c|c|c|c|c|c|c|c|c|c|c|c|c|c|c|c|}
\hline & \multicolumn{3}{|c|}{ Scenario 1} & \multicolumn{3}{|c|}{ Scenario 2} & \multicolumn{3}{|c|}{ Scenario 3} & \multicolumn{3}{|c|}{ Scenario 4} & \multicolumn{3}{|c|}{ Scenario 5} \\
\hline & Conv. & Pro. (MA) & Pro. (Opt.) & Conv. & Pro. (MA) & Pro. (Opt.) & Conv. & Pro. (MA) & Pro. (Opt.) & Conv. & Pro. (MA) & Pro. (Opt.) & Conv. & Pro. (MA) & Pro. (Opt.) \\
\hline $\begin{array}{l}\text { Maximum 1-Min } \\
\text { fluctuation of } P_{\mathrm{WF}}[\%]\end{array}$ & 22.1 & 17.0 & 17.2 & 21.8 & 15.5 & 15.5 & 18.6 & 12.4 & 13.0 & 19.9 & 14.3 & 14.4 & 17.9 & 12.8 & 14.2 \\
\hline $\begin{array}{l}\text { Average of 1-Min } \\
\text { fluctuation of } P_{\mathrm{WF}}[\%]\end{array}$ & 9.33 & 6.42 & 7.37 & 9.31 & 6.34 & 7.35 & 9.60 & 6.61 & 7.66 & 9.96 & 6.96 & 7.78 & 9.88 & 6.78 & 7.70 \\
\hline $\mathrm{SD}$ of $P_{\mathrm{WF}}$ [p.u.] & 0.0507 & 0.0411 & 0.0445 & 0.0456 & 0.0345 & 0.0387 & 0.0421 & 0.0306 & 0.0353 & 0.0496 & 0.0400 & 0.0424 & 0.0523 & 0.0433 & 0.0461 \\
\hline $\begin{array}{l}\text { Maximum 1-Min } \\
\text { fluctuation of } P_{\mathrm{g}}[\%]\end{array}$ & 9.86 & 9.65 & 9.97 & 8.24 & 8.21 & 8.35 & 7.28 & 6.72 & 7.25 & 8.50 & 9.10 & 9.19 & 7.22 & 7.20 & 7.68 \\
\hline $\begin{array}{l}\text { Average of 1-Min } \\
\text { fluctuation of } P_{\mathrm{g}}[\%]\end{array}$ & 3.39 & 3.27 & 3.76 & 3.32 & 3.21 & 3.73 & 3.47 & 3.37 & 3.90 & 3.56 & 3.51 & 3.93 & 3.55 & 3.42 & 3.90 \\
\hline SD of $P_{\mathrm{g}}$ [p.u.] & 0.0373 & 0.0344 & 0.0362 & 0.0257 & 0.0230 & 0.0252 & 0.0198 & 0.0180 & 0.0204 & 0.0307 & 0.0292 & 0.0303 & 0.0367 & 0.0351 & 0.0361 \\
\hline $\begin{array}{l}\text { Maximum power } \\
\text { of ESS [kW] }\end{array}$ & 7126.8 & 3592.0 & 3790.7 & 6713.4 & 3577.5 & 3707.3 & 6472.3 & 3294.9 & 3334.7 & 7844.9 & 4283.2 & 4310.5 & 7400.3 & 3902.8 & 3668.0 \\
\hline$E_{W F}^{\text {loss }}[\mathrm{kWh} / \mathrm{h}]$ & - & 367.1 & 192.0 & - & 349.6 & 162.9 & - & 353.2 & 166.8 & - & 494.7 & 345.3 & - & 505.9 & 292.9 \\
\hline$E_{\mathrm{ESS}}^{\text {lors }}[\mathrm{kWh} / \mathrm{h}]$ & 272.1 & 154.0 & 179.8 & 265.1 & 150.6 & 178.3 & 264.3 & 147.3 & 178.4 & 279.65 & 167.9 & 188.6 & 287.9 & 167.1 & 191.9 \\
\hline $\begin{array}{l}\text { Integral of } \\
\text { WF output }[\mathrm{MWh} / \mathrm{h}]\end{array}$ & 41.86 & 41.49 & 41.67 & 44.53 & 44.18 & 44.36 & 41.42 & 41.07 & 41.25 & 37.48 & 37.00 & 37.14 & 42.75 & 42.25 & 42.46 \\
\hline Battery life (Li-ion) [y] & 5.83 & 5.48 & 4.54 & 6.43 & 7.16 & 5.22 & 5.45 & 5.40 & 4.68 & 5.16 & 4.54 & 4.02 & 5.49 & 5.48 & 4.18 \\
\hline Battery life $(\mathrm{NaS})[y]$ & 15 & 15 & 15 & 15 & 15 & 15 & 15 & 15 & 15 & 15 & 15 & 15 & 15 & 15 & 15 \\
\hline
\end{tabular}




\subsection{Discussions}

This subsection calculates the cost and the profit of the proposed systems and the conventional system that is based on the simulation results presented in Section 5.1. Figures 16 and 17 show the total cost except for $C_{\mathrm{WF}}^{\mathrm{I}}\left(C_{\mathrm{WF}}^{\mathrm{I}}\right.$ is the same in all scenarios as shown in Table 3). Figures 18 and 19 and Table 7 summarize the cost except for $C_{\mathrm{WF}}^{\mathrm{I}}$, the profit and average of simulation results, respectively. It is clear that the proposed systems can increase the profit in the lifespan of WG (20 y). Especially, $C_{\mathrm{ESS}}^{\mathrm{I}}$ in both proposed systems are lower than that in the conventional system. The profit of the proposed system with the MA KE controller and with the optimal KE controller does not differ much when the Li-ion battery is used. By contrast, the profit of the proposed system with the optimal KE controller is the highest in those systems when the NaS battery is used. Consequently, both proposed systems increase the profit by approximately 5 [100 million JPY] as compared to the conventional system when the Li-ion battery is used, and the proposed system with the optimal KE control increases the profit by approximately 7 [100 million JPY] when compared to the conventional system when the NaS battery is used. Moreover, as shown in Table 7 , the proposed system not only satisfy the technical requirement, but also mitigate the SD of $P_{\mathrm{WF}}$ and $P_{\mathrm{g}}$.

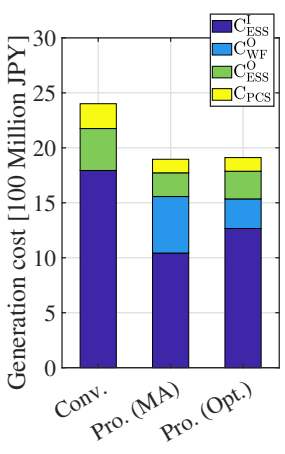

(a) Scenario 1

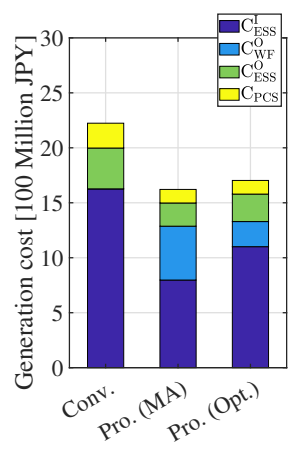

(b) Scenario 2

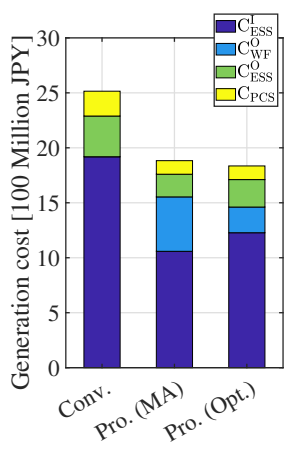

(c) Scenario 3

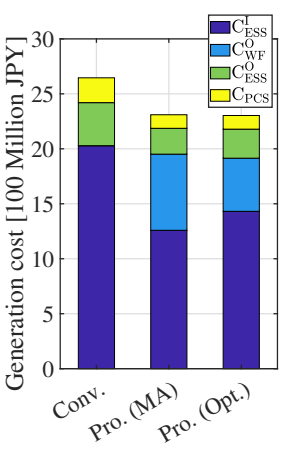

(d) Scenario 4

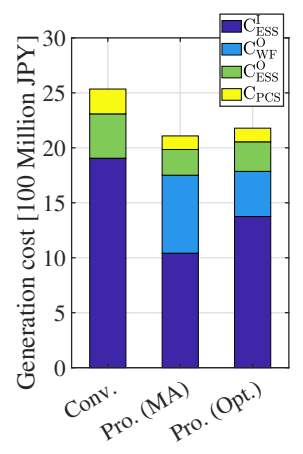

(e) Scenario 5

Figure 16. Cost (Li-ion battery).

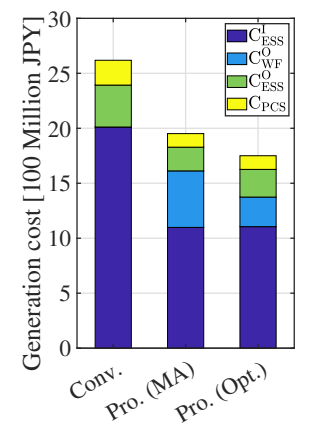

(a) Scenario 1

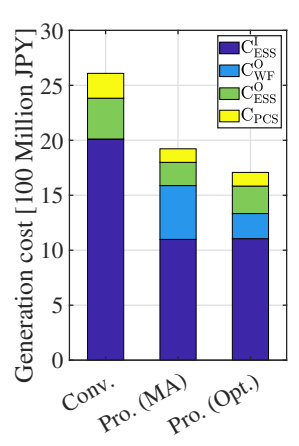

(b) Scenario 2

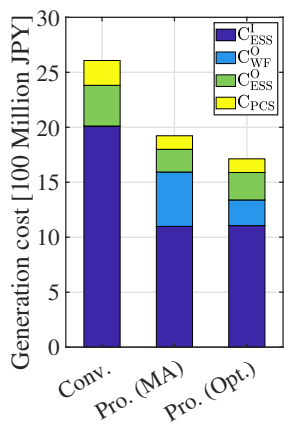

(c) Scenario 3

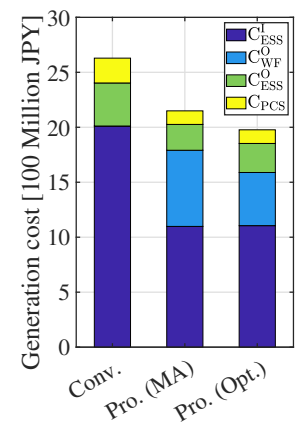

(d) Scenario 4

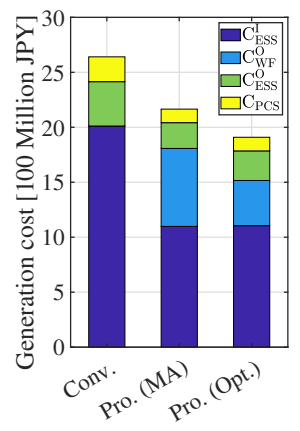

(e) Scenario 5

Figure 17. Cost (NaS battery). 


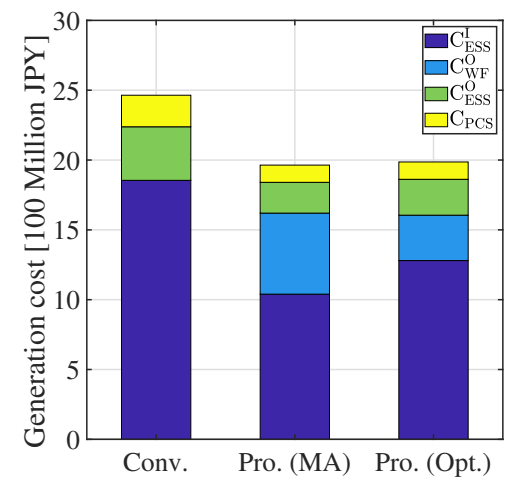

(a) Li-ion battery.

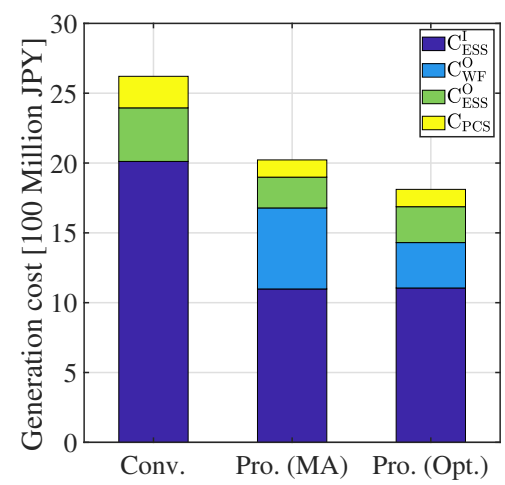

(b) NaS battery.

Figure 18. Average cost.

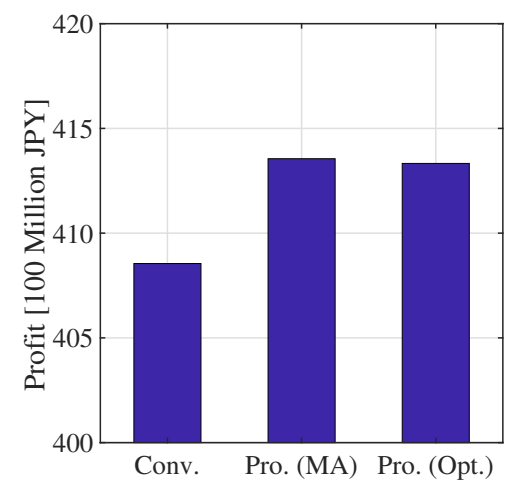

(a) Li-ion battery.

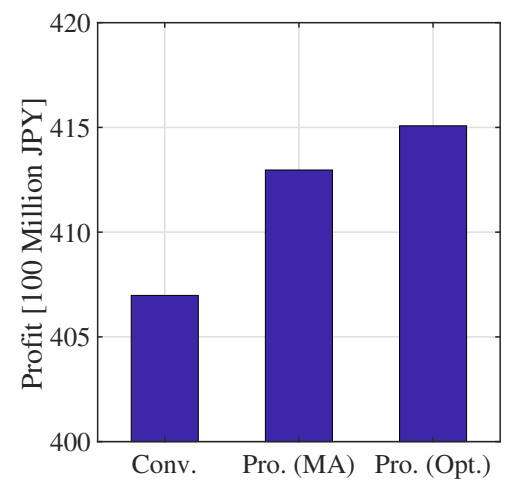

(b) NaS battery.

Figure 19. Average profit.

Table 7. Average of simulation results.

\begin{tabular}{lccc}
\hline & Conv. & Pro. (MA) & Pro. (Opt.) \\
\hline Maximum 1-Min fluctuation of $P_{\mathrm{WF}}[\%]$ & 20.1 & $14.4(-28.4 \%)$ & $14.9(-25.9 \%)$ \\
Average of 1-Min fluctuation of $P_{\mathrm{WF}}[\%]$ & 9.62 & $6.62(-31.2 \%)$ & $7.57(-21.3 \%)$ \\
SD of $P_{\mathrm{WF}}$ [p.u.] & 0.0481 & $0.0379(-21.2 \%)$ & $0.0414(-13.9 \%)$ \\
Maximum 1-Min fluctuation of $P_{\mathrm{g}}[\%]$ & 8.22 & $8.18(-0.487 \%)$ & $8.49(+3.28 \%)$ \\
Average of 1-Min fluctuation of $P_{\mathrm{g}}[\%]$ & 3.46 & $3.36(-2.89 \%)$ & $3.84(-11.0 \%)$ \\
SD of $P_{\mathrm{g}}[\mathrm{p} . \mathrm{u}]$. & 0.0300 & $0.0279(-7 \%)$ & $0.0296(-1.33 \%)$ \\
$E_{\mathrm{WF}}$ loss [kWh/h] & - & 414.1 & 232.0 \\
$E_{\mathrm{ESS}}^{\text {loss }}[\mathrm{kWh} / \mathrm{h}]$ & 273.8 & $157.4(-42.5 \%)$ & $183.4(-33.0 \%)$ \\
Integral of WF output [MWh/h] & 41.61 & $41.20(-0.985 \%)$ & $41.38(-0.553 \%)$ \\
Battery life (Li-ion) [y] & 5.67 & $5.61(-1.06 \%)$ & $4.53(-20.1 \%)$ \\
Battery life (NaS) [y] & 15 & 15 & 15 \\
Cost (Li-ion) [100 million JPY] & 22.38 & $18.40(-17.8 \%)$ & $18.62(-16.8 \%)$ \\
Cost (NaS) [100 million JPY] & 24.0 & $19.0(-20.8 \%)$ & $16.9(-29.6 \%)$ \\
Profit (Li-ion) [100 million JPY] & 410.81 & $414.79(+0.967 \%)$ & $414.57(+0.915 \%)$ \\
Profit (NaS) [100 million JPY] & 409.24 & $414.20(+1.21 \%)$ & $416.32(+1.73 \%)$ \\
\hline
\end{tabular}

\section{Conclusions}

This paper proposed a system that is composed of the ESS and the WF operated by the KE control. In addition, an optimal KE control was presented in order to consider the trade-off between the smoothing of WG output and the generating efficiency. Scenario simulations demonstrated that the proposed system could suppress the WF output fluctuation with a lower ESS rated power. Moreover, 
the cost of the proposed system was investigated through the simulation results. Numerical simulations demonstrated that the proposed system could reduce the total cost of the system and increase the profit in the lifespan of WG. As a result, the proposed system with the optimal KE control increased the profit by approximately $+0.967 \%$ to $+1.7 \%$ as compared to the conventional system. The SD of output power is reduced by approximately $1.33 \%$ to $1.7 \%$.

Author Contributions: K.K. and K.-Z.L. developed the basic concept. K.K. performed the simulation analysis. T.T.calculates the cost of the system. K.K. and M.W. developed an optimal kinetic energy control. K.-Z.L., T.Z. and J.T. revised this manuscript. K.K. wrote this manuscript. All authors have read and agreed to the published version of the manuscript.

Funding: This work was supported in part by the Japan Society for the Promotion of Science under Grant G19K04452 and in part by Yashima Environment Technology Foundation of Japan.

Conflicts of Interest: The authors declare no conflict of interest.

\section{Abbreviations}

$\begin{array}{ll}\text { ESS } & \text { Energy storage system } \\ \text { WF } & \text { Wind farm } \\ \text { KE } & \text { Kinetic energy } \\ \text { MA } & \text { Moving average } \\ \text { FLF } & \text { First-order low-pass filter } \\ \text { WG } & \text { Wind generator } \\ \text { MPPT } & \text { maximum power point tracking } \\ \text { SOC } & \text { State-of-charge } \\ \text { PCS } & \text { Power converter system } \\ \text { JPY } & \text { Japanese yen } \\ \text { DOD } & \text { Depth of discharge } \\ \text { SD } & \text { Standard deviation }\end{array}$

\section{Nomenclature}

$\begin{array}{ll}n & \text { Number of WGs } \\ V & \text { Wind speed } \\ \omega & \text { Mechanical rotor angular frequency } \\ P & \text { WG output } \\ P_{\mathrm{WF}} & \text { WF output } \\ P_{\mathrm{b}} & \text { ESS output } \\ P_{\mathrm{g}}\left(=P_{\mathrm{WF}}-P_{\mathrm{b}}\right) & \text { Combined output power } \\ \rho & \text { Air-density } \\ R & \text { Radius of rotor blade } \\ \lambda & \text { Tip speed ratio } \\ \beta & \text { Blade pitch angle } \\ C_{\mathrm{p}} & \text { Power coefficien } \\ H & \text { Inertia constant of WG } \\ T_{\mathrm{m}} & \text { Mechanical torque } \\ T_{\mathrm{e}} & \text { Electrical torque } \\ P_{\mathrm{mppt}} & \text { MPPT output reference } \\ P_{\mathrm{loss}} & \text { Charge/discharge loss of the ESS } \\ A & \text { SOC-FB gain } \\ K_{\mathrm{p}} & \text { Gain of ESS controller } \\ a_{0}, a_{1} & \text { Parameter of ESS controller } \\ \Delta F_{\mathrm{g}} & \text { Fluctuation ratio of combined output } \\ E & \text { Remaining energy of ESS } \\ \Delta P_{\mathrm{WF}} & \text { Short-period components of the WF output } \\ P_{\mathrm{WF}}^{\mathrm{MA}} & \text { MA of } P_{\mathrm{WF}} \\ \Delta P_{\mathrm{pu}} & \text { Fluctuation component of WG } \\ q & \text { Nonlinear weight } \\ K_{\mathrm{q}} & \text { Weight } \\ \alpha & \text { Exponent weight } \\ & \end{array}$




$\begin{array}{ll}C_{\mathrm{WF}}^{\mathrm{I}} & \text { Installation cost of WF } \\ C_{\mathrm{WF}}^{\mathrm{O}} & \text { Opportunity loss of WF } \\ C_{\mathrm{ESS}}^{\mathrm{I}} & \text { Installation cost of ESS } \\ C_{\mathrm{ESS}}^{\mathrm{O}} & \text { Opportunity loss of ESS } \\ C_{\mathrm{PCS}} & \text { Cost of PCS } \\ E_{\mathrm{WF}}^{\text {loss }} & \text { Energy loss by KE control } \\ C_{\mathrm{rate}} & \text { C-rate } \\ E_{\mathrm{ESS}}^{\text {loss }} & \text { Integral of the charge/discharge loss } \\ L_{\text {cal }} & \text { Calendar life } \\ L^{\text {cyc }} & \text { Cycle life } \\ \text { Subscript } & \\ \text { pu } & \text { Per-unit } \\ \mathrm{n} & \text { rated value } \\ \text { Superscript } & \\ \text { ref } & \text { Reference value }\end{array}$

\section{References}

1. Global Wind Energy Council. Global Wind Report 2018. 2019. Available online: http://www.gwec.net/ (accessed on 24 September 2020).

2. Liu, Y.; Du, W.; Xiao, L.; Wang, H.; Cao, J. A Method for Sizing Energy Storage System to Increase Wind Penetration as Limited by Grid Frequency Deviations. IEEE Trans. Power Syst. 2016, 31, 729-737. [CrossRef]

3. Cao, J.; Du, W.; Wang, H.; McCulloch, M. Optimal Sizing and Control Strategies for Hybrid Storage System as Limited by Grid Frequency Deviations. IEEE Trans. Power Syst. 2018, 33, 5486-5495. [CrossRef]

4. Koiwa, K.; Liu, K.; Tamura, J. Analysis and Design of Filters for the Energy Storage System: Optimal Tradeoff Between Frequency Guarantee and Energy Capacity/Power Rating. IEEE Trans. Ind. Electron. 2018, 65, 6560-6570. [CrossRef]

5. Tsili, M.; Papathanassiou, S. A review of grid code technical requirements for wind farms. IET Renew. Power Gener. 2009, 3, 308-332. [CrossRef]

6. Nguyen, C.; Lee, H. Optimization of power dispatch to minimize battery storage capacity in wind farm. In Proceedings of the 2014 IEEE Energy Conversion Congress and Exposition (ECCE), Pittsburgh, PA, USA, 14-18 September 2014; pp. 420-427.

7. Nguyen, C.; Lee, H. Power Management Approach to Minimize Battery Capacity in Wind Energy Conversion Systems. IEEE Trans. Ind. Appl. 2017, 53, 4843-4854. [CrossRef]

8. Yoshimoto, K.; Nanahara, T.; Koshimizu, G. New Control Method for Regulating State-of- Charge of a Battery in Hybrid Wind Power/Battery Energy Storage System. In Proceedings of the 2006 IEEE PES Power Systems Conference and Exposition, Atlanta, GA, USA, 29 October-1 November 2006; pp. 1244-1251.

9. Kurose, N.; Takahashi, R.; Tamura, J.; Fukushima, T.; Sasano, E.; Shinya, K. A consideration on the determination of power rating of Energy Storage System for smoothing wind generator output. In Proceedings of the Electrical Machines and Systems (ICEMS), Incheon, Korea, 10-13 October 2010; pp. 622-627.

10. Zhao, H.; Wu, Q.; Hu, S.; Xu, H.; Rasmussen, C.N. Review of energy storage system for wind power integration support. Appl. Energy 2015, 137, 545-553. [CrossRef]

11. Zou, J.; Peng, C.; Shi, J.; Xin, X.; Zhang, Z. State-of-charge optimising control approach of battery energy storage system for wind farm. IET Renew. Power Gener. 2015, 9, 647-652. [CrossRef]

12. Lin, F.; Chiang, H.; Chang, J.; Chang, Y. Intelligent wind power smoothing control with BESS. IET Renew. Power Gener. 2017, 11, 398-407. [CrossRef]

13. Lamsal, D.; Sreeram, V.; Mishra, Y.; Kumar, D. Achieving a minimum power fluctuation rate in wind and photovoltaic output power using discrete Kalman filter based on weighted average approach. IET Renew. Power Gener. 2018, 12, 633-638. [CrossRef]

14. Koiwa, K.; Ishii, T.; Liu, K.; Zanma, T.; Tamura, J. On the Reduction of the Rated Power of Energy Storage System in Wind Farms. IEEE Trans. Power Syst. 2020, 35, 2586-2596. [CrossRef]

15. Senjyu, T.; Sakamoto, R.; Urasaki, N.; Funabashi, T.; Fujita, H.; Sekine, H. Output power leveling of wind turbine Generator for all operating regions by pitch angle control. IEEE Trans. Energy Convers. 2006, 21, 467-475. [CrossRef] 
16. Chowdhury, M.A.; Hosseinzadeh, N.; Shen, W. Fuzzy logic systems for pitch angle controller for smoothing wind power fluctuations during below rated wind incidents. In Proceedings of the 2011 IEEE Trondheim PowerTech, Trondheim, Norway, 19-23 June 2011; pp. 1-7.

17. Chowdhury, M.; Hosseinzadeh, N.; Shen, W. Smoothing wind power fluctuations by fuzzy logic pitch angle controller. Renew. Energy 2012, 38, 224-233. [CrossRef]

18. Sato, D.; Saitoh, H. Smoothing Control of Wind Farm Output by Using Kinetic Energy of Variable Speed Wind Power Generators. IEEJ Trans. Power Energy 2009, 129, 580-590. [CrossRef]

19. Varzaneh, S.G.; Gharehpetian, G.; Abedi, M. Output power smoothing of variable speed wind farms using rotor-inertia. Electr. Power Syst. Res. 2014, 116, 208-217. [CrossRef]

20. Howlader, A.M.; Urasaki, N.; Pratap, A.; Senjyu, T.; Saber, A.Y. A fuzzy control strategy for power smoothing and grid dynamic response enrichment of a grid-connected wind energy conversion system. Wind Energy 2014, 17, 1347-1363. [CrossRef]

21. Zhao, X.; Yan, Z.; Zhang, X. A Wind-Wave Farm System With Self-Energy Storage and Smoothed Power Output. IEEE Access 2016, 4, 8634-8642. [CrossRef]

22. Rosyadi, M.; Umemura, A.; Takahashi, R.; Tamura, J.; Uchiyama, N.; Ide, K. Simplified Model of Variable Speed Wind Turbine Generator for Dynamic Simulation Analysis. IEEJ Trans. Power Energy 2015, 135, 538-549. [CrossRef]

23. Hazari, M.R.; Mannan, M.A.; Muyeen, S.M.; Umemura, A.; Takahashi, R.; Tamura, J. Stability Augmentation of a Grid-Connected Wind Farm by Fuzzy-Logic-Controlled DFIG-Based Wind Turbines. Appl. Sci. 2018, 8, 20. [CrossRef]

24. Rosyadi, M.; Muyeen, S.M.; Takahashi, R.; Tamura, J. New controller design for PMSG based wind generator with LCL-filter considered. In Proceedings of the 2012 XXth International Conference on Electrical Machines, Marseille, France, 12 November 2012; pp. 2112-2118.

25. Koiwa, K.; Sato, H.; Umemura, A.; Takahashi, R.; Tamura, J. Frequency Control of Power System by Output Frequency Band Control of Wind Farm by Variable Speed Wind Generators. IEEJ Trans. Power Energy 2015, 135, 351-361. [CrossRef]

26. Tamura, S. Economic Analysis of Hybrid Battery Energy Storage Systems Applied to Frequency Control in Power System. Electr. Eng. Jpn. 2016, 195, 24-31. [CrossRef]

27. Investigating R\&D Committee on Application and Control Technology of Battery Energy Storage for Power Systems. In Application and Control Technology of Battery Energy Storage for Power Systems; The Institute of Electrical Engineers of Japan: Tokyo, Japan, 2017.

28. Kintner-Meyer, M.C.W.; Balducci, P.J.; Jin, C.; Nguyen, T.B.; Elizondo, M.A.; Viswanathan, V.V.; Guo, X.; Tuffner, F.K. Energy Storage for Power Systems Applications: A Regional Assessment for the Northwest Power Pool (NWPP); Pacific Northwest National Laboratory: Richland, WA, USA, 2010.

29. Gee, A.M.; Robinson, F.V.P.; Dunn, R.W. Analysis of Battery Lifetime Extension in a Small-Scale Wind-Energy System Using Supercapacitors. IEEE Trans. Energy Convers. 2013, 28, 24-33. [CrossRef]

30. Alam, M.J.E.; Saha, T.K. Cycle-life degradation assessment of Battery Energy Storage Systems caused by solar PV variability. In Proceedings of the 2016 IEEE Power and Energy Society General Meeting (PESGM), Boston, MA, USA, 17-21 July 2016; pp. 1-5.

31. Agency for Natural Resources and Energy. 2019. Available online: https://www.meti.go.jp/shingikai/santeii/ pdf/049_01_00.pdf (accessed on 24 September 2020).

32. International Renewable Energy Agency. Electricity Storage and Renewables for Island Power: A Guide for Decision Makers. 2012. Available online: https://irena.org/publications/ (accessed on 24 September 2020).

33. Mongird, K.; Fotedar, V.; Viswanathan, V.; Koritarov, V.; Balducci, P.; Hadjerioua, B.; Alam, J. Energy Storage Technology and Cost Characterization Report; U.S. Department of Energy's Water Power Technologies Office by Pacific Northwest National Laboratory: Washington, DC, USA, 2019.

Publisher's Note: MDPI stays neutral with regard to jurisdictional claims in published maps and institutional affiliations. 